\title{
POTENSI RUANG SEMPADAN SUNGAI UNTUK PEMENUHAN KEBUTUHAN RUANG TERBUKA HIJAU TAMAN KOTA SEMARANG
}

\author{
Jamilla Kautsary ${ }^{1}$ \\ Boby Rahman ${ }^{2}$ \\ Salmaa Shafira ${ }^{3}$ \\ 1,2,3 Program Studi Teknik Perencanaan Wilayah dan Kota, Universitas Islam Sultan Agung Semarang \\ ${ }^{1}$ Penulis Korespondensi e-mail: jamilla@unissula.ac.id
}

\begin{abstract}
ABSTRACK
The existence of green open space in urban areas is very important not only in terms of aesthetics and ecology, but also socially and economically. The existence of this space has become very scarce and difficult to fulfill, due to the lack of land scarcity in urban areas. The Efforts to fulfill RTH in general in urban areas are only based on the consideration $30 \%$ of urban area (with $20 \%$ of public green open space and $10 \%$ of private green open space), This study on the potential of green open space for river borders is located in the city of Semarang, with a calculation approach according to the standard of the Minister of Public Works Regulation. No. 5/2008, and used the GIS program as analysis tools. The results triangulated with institutional data and field data. It shows that there is a large enough potential for RTH on riverbanks $(11.95 \%$ of the $1.5 \%$ that togetter with others functions green open spaces). Apart of this potential can use to fulfillt of the lack of city park green open space needs, which it currently the average achievement is only $3.776 \%$ of the determined $12.5 \%$.
\end{abstract}

Keywords: Public Green Open Space, River Border, City Park

\begin{abstract}
ABSTRAK
Ruang Terbuka Hijau (RTH) di perkotaan keberadaannya sangat penting tidak hanya dari sisi estetik, dan ekologis, tetapi juga secara sosial dan ekonomi. Keberadaan ruang ini, menjadi sangat langka dan sulit untuk dipenuhi, akibat kurangnya langkanya lahan di perkotaan. Upaya pemenuhan RTH secara umum hanya didasarkan pada pertimbangan pemenuhan angka 30\% luas perkotaan dengan perincian $20 \%$ publik dan 10\% RTH privat, tanpa melihat detailnya sesuai dengan pedoman teknis yang berlaku di Indonesia. Kajian potensi RTH sempadan sungai ini berlokasi di Kota Semarang, dengan pendekatan perhitungan terinci sesuai standar Peraturan Menteri Pekerjaan Umum No. 5 Tahun 2008. Identifikasi luasan dibantu dengan alat analisis GIS yang di triangulasikan dengan data primer dan sekunder. Hasil perhitungan yang menunjukkan ada potensi yang cukup besar untuk RTH sempadan sungai sebesar 11,95\% (dari yang seharusnya 1,5\% bersama RTH fungsi tertentu lainnya). Potensi kelebihan ini sebagian tentu bisa dimanfaatkan untuk pemenuhan RTH taman kota yang saat ini capaiannya rata-rata hanya sebesar 3,776\% dari 12,5\% yang di tentukan.
\end{abstract}

Kata Kunci: RTH publik, Taman Kota dan Sempadan Sungai 


\section{PENDAHULUAN}

Permasalahan tata ruang kota serta penyediaan ruang terbuka hijau terus meningkat. Permasalahan ini jika tidak dikendalikan akan dapat menyebabkan terjadinya perubahan ekologis lingkungan perkotaan serta dapat penurunan kualitas lingkungan (Fadhila, Murtilaksono, \& Munibah, 2019). Perencanaan kota yang tidak mengakomodasi penyediaan lahan untuk RTH dari awal juga akan mengalami kesulitan akibat naiknya nilai lahan. Banyaknya permasalahan ikutan yang muncul dan kemudian menjadi problem yang cukup pelik untuk di atasi. Kondisi ini membawa konsekuensi negatif pada kehidupan perkotaan. Beragam aspek kehidupan di perkotaan mulai terkikis dari dampak kerusakan ekologi. Pemasalahan banjir, polusi udara, meningkatnya timbunan sampah, telah memperburuk ekosistem perkotaan telah yang menjadikan lingkungan perkotaan kurang sehat secara fisik dan pisikologis. Akibatnya banyak masyarakat perkotaan yang stress (Siwi, 2018). Permasalahan RTH ini kemudian berkembang tidak hanya masalah fisik tetapi juga ditambah dengan masalah pengelolaan (Nugroho, 2015)

RTH perkotaan secara ekologis memiliki peran yang sangat penting karena RTH menawarkan naungan dan pendinginan, untuk mengurangi efek hawa panas pada kota-kota di daerah tropis, dan mengurangi polusi udara (Rakhshandehroo, Johari, \& Yusof, 2018). RTH di perkotaan juga memberikan berbagai kegunaan dan efek signifikan pada pengaturan tingkat kenyamanan di perkotaan. RTH adalah aktor penting dalam upaya menciptakan kota menjadi lebih tenang dari tekanan lingkungan, kebisingan ekstrim, dan kemacetan lalu lintas (Abu Kasim, Yusof, \& Zulhaidi Mohd Shafri, 2019).

Di perkotaan di Indonesia secara umum, standar kebutuhan RTH di perkotaan minimal adalah 30\% dari luas perkotaan. Luasan ini dibagi menjadi 20\% RTH publik dan 10\% RTH privat. RTH publik di perkotaan meliputi RTH Taman dan Hutan Kota, RTH Jalur Hijau Jalan, RTH Fungsi Tertentu yang terdiri dari RTH Sempadan, Pengaman dan Pemakaman (Pemerintah Repulik Indonesia, 2008). Keberadaan RTH taman kota saat ini semakin dibutuhkan. Hal ini berkaitan dengan fungsi utama (fungsi ekologis) dan fungsi tambahan (fungsi arsitektural, sosial dan ekonomi). Ketika terjadi tekanan baru berupa pandemi Covid-19, banyak masyarakat yang baru menyadari pentingnya RTH publik untuk kebutuhan hidup sehat. RTH privat yang mereka miliki, telah banyak yang beralih fungsi sebagai garasi/carport, ruang tamu, kamar tidur atau ruang terbangun lainnya. Akibatnya, ketika mereka mulai menjalankan berbagai kegiatan dari rumah dan membutuhkan ruang luar untuk sekedar berjemur atau untuk mengatasi kejenuhan aktivitas di rumah, RTH sudah 
tidak ada. Guna memenuhi gaya hidup sehat di era pandemi Covid-19, akhirnya bayak masyarakat yang menggunakan ruang jalan untuk berjemur, berolah raga atau bersosialisasi dengan tetangga dengan menerapkan jarak fisik (Ahmad, Tedy, 2020)

Berdasarkan penelitian sebelumnya yang dilakukan penelitian bersama Pemerintah Provinsi Jawa Tengah, tentang Studi Potensi Pemenuhan RTH Perkotaan Provinsi Jawa Tengah 2019, ditemukan adanya permasalahan pemenuhan persentase luasan RTH Taman Kota hampir untuk semua perkotaan di Provinsi Jawa Tengah. Persentase luasan RTH Taman Kota yang seharusnya $12,5 \%$ dari luas perkotaan, rata-rata baru tercapai $0,88 \%$, sementara untuk RTH fungsi tertentu yang seharusnya 1,5\% tetapi tersedia 6,09\%. Khusus untuk Kota Semarang sebagai Ibukota Provinsi Jawa Tengah dengan luas Kota 38799,92 Ha, capaian persentase luasan taman kota sebesar 0,60\% dari luas kota. Sementara untuk RTH fungsi tertentu capainnya 6,56\% (Pemerintah Provinsi Jawa Tengah, 2019). Permasalahan penyediaan RTH Kota Semarang ini sudah teridentifikasi sejak tahun 2015. Angka persentase pemenuhan RTH Kota Semarang tahun 2015 sebesar 7,31\% (untuk luas total RTH publik sebesar 20\%) dari luas wilayah kota Semarang (Nugroho, 2015)

Artikel penelitian ini bertujuan untuk mengkaji besaran potensi ruang sempadan sungai di Kota Semarang yang teridentifikasi memiliki potensi kelebihan, agar dapat dipergunakan untuk penambahan persentase RTH taman di Kota Semarang. Permasalahan atau gap pemenuhan ruang terbuka hijau publik taman kota yaitu masalah keterbatasan lahan yang dengan adanya penelitian ini diharapkan akan dapat diperkecil. Pemilihan ruang sempadan sungai ini selain secara potensi keruangan juga masih ada, secara estetik dan lingkungan juga akan banyak menyelesaikan beberapa masalah ruang di kawasan perkotaan khususnya ruang sempadan sungai yang saat ini kebanyakan digunakan sebagai area kotor seperti tempat pembuangan sampah, toilet umum atau untuk permukiman kumuh ilegal (Alifia, 2016).

\section{METODOLOGI}

\section{a) KONSEPSI}

Ruang Terbuka Hijau (RTH) merupakan ruang terbuka bervegetasi yang berada di kawasan perkotaan yang mempunyai fungsi antara lain sebagai area rekreasi, sosial budaya, estetika, fisik kota, ekologis dan memiliki nilai ekonomis yang cukup tinggi bagi manusia maupun bagi pengembangan kota (Setyani, Risma, Sitorus, \& Panuju, 2017). Pada umumnya RTH didominasi oleh tanaman dan tumbuhan, dimana unsur ini banyak 
berpengaruh terhadap kualitas udara kota. Tanaman dapat menciptakan iklim mikro, yaitu adanya penurunan suhu sekitar, kelembaban yang cukup, kadar O2 yang bertambah. Tanaman yang ada di Taman dan hutan kota juga dapat menyerap CO2 di udara yang dihasilkan oleh berbagai kegiatan seperti industri, kendaraan bermotor dan sebagainya (Hakim, R., 2004).

RTH secara umum dapat dibagi mejadi RTH publik dan privat. RTH dapat berbentuk hutan kota, taman kota, taman pemakaman umum, lapangan olahraga, jalur hijau, jalan raya, bantaran rel kereta api, dan bantaran sungai (Setyani et al., 2017). Khusus RTH publik yaitu merupakan RTH yang dimiliki dan dikelola oleh pemerintah daerah yang digunakan untuk kepentingan masyarakat secara umum. RTH publik ini dapat berbentuk taman dan hutan kota, jalur hijau jalan raya, dan RTH fungsi tertentu yang berupa sempadan rel kereta api, sempadan sungai, pemakaman (Pemerintah Repulik Indonesia, 2008).

Tujuan dari penyelenggaraan RTH berdasarkan Peraturan Menteri Pekerjaan Umum Nomor 05/PRT/M/2008 tentang Pedoman Penyediaan dan Pemanfaatan RTH di Kawasan Perkotaan adalah untuk menjaga ketersediaan lahan sebagai kawasan resapan air, menciptakan aspek planologis perkotaan melalui keseimbangan antara lingkungan yang bermanfaat untuk kepentingan masyarakat kota, meningkatkan keserasian lingkungan perkotaan sehingga perkotaan akan lebih aman, nyaman, segar, indah dan bersih. Fungsifungsi utama tersebut dapat dikombinasikan sesuai dengan kebutuhan, kepentingan, dan keberlanjutan kota, terutama perlindungan tata air, keseimbangan ekologi dan konservasi sumber hayati (Pemerintah Repulik Indonesia, 2008).

Pada banyak kasus penelitian RTH di Indonesia, Peneliti hanya menghitung perkiraan kebutuhan RTH dari kebutuhan yang digariskan di Undang-Undang No. 26 Tahun 2007 tentang Penataan Ruang dan beberapa turunannya, yang hanya membagi RTH berdasarkan penyediannya sejumlah $30 \%$ dari luas perkotaan, dengan rincian $10 \% \mathrm{RTH}$ publik dan $20 \%$ privat. Kondisi ini banyak menyebabkan masalah pemenuhan RTH publik sulit terselesaikan. Padahal jika di cermati dengan baik, standar persentase luasan minimal RTH publik sesuai dengan pedoman teknis yang ada di Peraturan Menteri Pekerjaan Umum Nomor 05/PRT/M/2008 terdapat rincian perhitungan untuk tiap jenis RTH. Rincian ini tidak banyak diketahui oleh pemerintah kabupaten/kota maupun oleh peneliti. Rincian pembagian luasan RTH berdasarkan jenis ini secara rinci dapat dilihat pada Gambar 1 Diagram Standar Minimal Persentase Luasan Minimal RTH di Perkotaan 
Khusus untuk RTH sempadan sungai sesuai dengan Peraturan Menteri Pekerjaan Umum No. 28 Tahun 2015, diartikan sebagai ruang jalur hijau yang terletak di bagian kiri dan kanan sungai yang memiliki fungsi utama untuk melindungi sungai tersebut dari berbagai gangguan yang dapat merusak kondisi sungai dan kelestariannya. Pemanfaatan RTH daerah sempadan sungai dilakukan untuk kawasan konservasi, perlindungan tepi kirikanan bantaran sungai yang rawan erosi, pelestarian, peningkatan fungsi sungai, mencegah okupasi penduduk yang mudah menyebabkan erosi, dan pengendalian daya rusak sungai melalui kegiatan penatagunaan, perizinan, dan pemantauan.

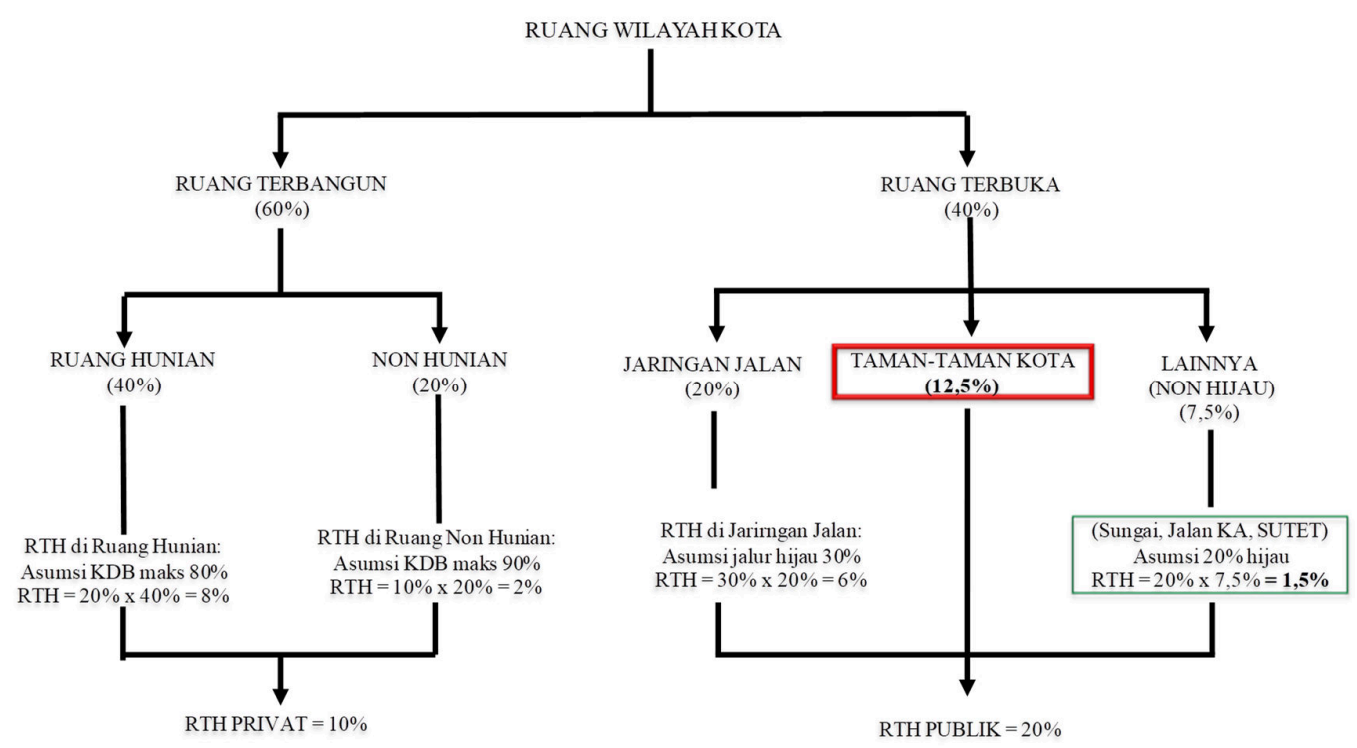

Gambar 1. Diagram Standar Minimal Persentase Luasan Minimal RTH di Perkotaan Sumber: (Pemerintah Repulik Indonesia, 2008)

Pada Lampiran I Peraturan Menteri Pekerjaan Umum tersebut upaya penetapan ruang sempadan sungai dimaksudkan untuk penyangga ekosistem khususnya antara ekosistem perairan atau sungai dengan ekosistem daratan. Zona sempadan ini biasanya didominasi sebagai tempat tumbuh beberapa jenis tanaman liar dan/atau lahan basah berupa rumput, semak, atau pun tanaman tahunan yang ditanam di sepanjang tepi sungai (Pemerintah Republik Indonesia, 2015).

Parameter yang akan dikaji pada artikel dengan rincian standar minimal dan permasalahan yang sudah diuraikan di atas adalah:

i. Persentase luasan RTH publik dan kekurangannya

ii. Persentase luasan RTH publik taman kota dan kekurangnya

iii. Potensi RTH Sempadan Sungai dan pemanfaatannya 
Pada artikel ini analisis persentase capaian luasan RTH publik akan dihitung berdasarkan rincian seperti pada Gambar 1, dan lebih dikhusukan pada perhitungan RTH publik taman dan hutan kota serta RTH fungsi Khusus sempadan sungai. Perhitungan kecukupan akan dilakukan dengan mengkomparasikan antara standar minimal berupa persentase luasan seperti yang di arahkan dalam Peraturan Menteri Pekerjaan Umum dengan luasan eksisting RTH jenis tersebut yang dikenali dari hasil identifiksi data spasial dengan bantuan program GIS dan ditriangulasikan dengan data primer serta sekunder dari Instansi Pengelola RTH Publik di Kota Semarang. Hasil perhitungan persentase luasan capaian akan disandingkan dengan luasan ideal atau standar. Kelebihan luasan perhitungan RTH sempadan sungai akan dijadikan temuan potensi RTH fungsi tertentu yang sebagian dapat dimanfaatkan untuk menambah luasan RTH taman dan hutan kota.

\section{HASIL DAN PEMBAHASAN}

\section{1) Persentase Luasan RTH Publik dan Kekurangannya}

Luas eksisting RTH publik di Semarang dari olah data spasial yang diperbaharui dengan survey primer untuk pemenuhan RTH Publik secara umum, terdapat 2 kecamatan (Kecamatan Gayamsari dan Kecamatan Semarang Utara) yang sudah melampaui standar minimal 20\% dari luas perkotaannya, sementara 14 kecamatan lainnya angka capaian masih jauh dari standar minimal luasan RTH publik. Satu-satunya kecamatan yang sudah memiliki angka capaian luasan RTH publik taman kota adalah Kecamatan Candisari. Hal ini dikarenakan kecamatan ini sejak jaman penjajahan Belanda sudah merencanakan kebutuhan RTH dengan baik. Sementara jika diamati lebih seksama pada Tabel 1, angka capaian unuk beberapa kecamatan untuk RTH taman kota bahkan 0\%. Besaran angka capaian RTH publik secara keseluruhan disumbang dari luasan/besaran persentase RTH fungsi khusus.

Tabel 1. Kondisi Capaian RTH Publik Kota Semarang Per Kecamatan Tahun 2020

\begin{tabular}{|l|c|c|c|c|c|c|c|c|}
\hline \multirow{2}{*}{ Kecamatan } & $\begin{array}{c}\text { Luas } \\
\text { Kec. } \\
\text { (Ha) }\end{array}$ & $\begin{array}{c}\text { L RTH } \\
\text { Taman } \\
\text { dan } \\
\text { Hutan } \\
\text { Kota } \\
\text { (Ha) }\end{array}$ & $\begin{array}{c}\text { Luasan } \\
\text { RTH }\end{array}$ & $\begin{array}{c}\text { L RTH } \\
\text { Jalur } \\
\text { Hijau } \\
\text { Jln }\end{array}$ & $\begin{array}{c}\text { Luas } \\
\text { an }\end{array}$ & $\begin{array}{c}\text { L RTH } \\
\text { Fungsi } \\
\text { Khusus }\end{array}$ & $\begin{array}{c}\text { Luasan } \\
\text { RTH }\end{array}$ & $\begin{array}{c}\text { Total } \\
\text { Luas } \\
\text { Luan }\end{array}$ \\
\hline Banyumanik & 3055,62 & 17,1 & $0,56 \%$ & & $\begin{array}{c}0,00 \\
\%\end{array}$ & 144,89 & $4,74 \%$ & $5,30 \%$ \\
\hline Candisari & 703,02 & 12,75 & $1,81 \%$ & 0,51 & $\begin{array}{c}0,07 \\
\%\end{array}$ & 71,38 & $10,15 \%$ & $12,04 \%$ \\
\hline Gajahmungkur & 959,7 & 3,55 & $0,37 \%$ & & $\begin{array}{c}0,00 \\
\%\end{array}$ & 49,47 & $5,15 \%$ & $5,52 \%$ \\
\hline
\end{tabular}




\begin{tabular}{|c|c|c|c|c|c|c|c|c|}
\hline Kecamatan & $\begin{array}{l}\text { Luas } \\
\text { Kec. } \\
\text { (Ha) }\end{array}$ & $\begin{array}{c}\text { L RTH } \\
\text { Taman } \\
\text { dan } \\
\text { Hutan } \\
\text { Kota } \\
\text { (Ha) }\end{array}$ & $\begin{array}{c}\% \\
\text { Luasan } \\
\text { RTH }\end{array}$ & $\begin{array}{c}\text { L RTH } \\
\text { Jalur } \\
\text { Hijau } \\
\text { Jln }\end{array}$ & $\begin{array}{c}\% \\
\text { Luas } \\
\text { an }\end{array}$ & $\begin{array}{c}\text { L RTH } \\
\text { Fungsi } \\
\text { Khusus }\end{array}$ & $\begin{array}{c}\% \\
\text { Luasan } \\
\text { RTH }\end{array}$ & $\begin{array}{c}\text { Total } \\
\text { \%e } \\
\text { Luasan }\end{array}$ \\
\hline Gayamsari & 612,77 & 0 & $0,00 \%$ & & $\begin{array}{c}0,00 \\
\%\end{array}$ & 127,26 & $20,77 \%$ & $20,77 \%$ \\
\hline Genuk & 2756,61 & 3,86 & $0,14 \%$ & 1,5 & $\begin{array}{c}0,05 \\
\%\end{array}$ & 294,22 & $10,67 \%$ & $10,87 \%$ \\
\hline Gunung Pati & 6084,21 & 0 & $0,00 \%$ & & $\begin{array}{c}0,00 \\
\%\end{array}$ & 191,24 & $3,14 \%$ & $3,14 \%$ \\
\hline Mijen & 5887,7 & 0 & $0,00 \%$ & 0,1 & $\begin{array}{c}0,00 \\
\%\end{array}$ & 210,04 & $3,57 \%$ & $3,57 \%$ \\
\hline Ngaliyan & 4424,15 & 0 & $0,00 \%$ & & $\begin{array}{c}0,00 \\
\%\end{array}$ & 189,57 & $4,28 \%$ & $4,28 \%$ \\
\hline Pedurungan & 2319,82 & 0 & $0,00 \%$ & 1,4718 & $\begin{array}{c}0,06 \\
\%\end{array}$ & 170,48 & $7,35 \%$ & $7,41 \%$ \\
\hline $\begin{array}{l}\text { Semarang } \\
\text { Barat }\end{array}$ & 2222,76 & 1,49 & $0,07 \%$ & 1,8 & $\begin{array}{c}0,08 \\
\%\end{array}$ & 232,59 & $10,46 \%$ & $10,61 \%$ \\
\hline $\begin{array}{l}\text { Semarang } \\
\text { Selatan }\end{array}$ & 621,91 & 2,2 & $0,35 \%$ & 0,55 & $\begin{array}{c}0,09 \\
\%\end{array}$ & 74,46 & $11,97 \%$ & $12,41 \%$ \\
\hline $\begin{array}{l}\text { Semarang } \\
\text { Tengah }\end{array}$ & 535,39 & 2,92 & $0,55 \%$ & 0,25 & $\begin{array}{c}0,05 \\
\%\end{array}$ & 27,99 & $5,23 \%$ & $5,82 \%$ \\
\hline $\begin{array}{l}\text { Semarang } \\
\text { Timur }\end{array}$ & 559,46 & 1,32 & $0,24 \%$ & 0,46 & $\begin{array}{c}0,08 \\
\%\end{array}$ & 52,6 & $9,40 \%$ & $9,72 \%$ \\
\hline $\begin{array}{l}\text { Semarang } \\
\text { Utara }\end{array}$ & 1072,91 & 0,73 & $0,07 \%$ & & $\begin{array}{c}0,00 \\
\%\end{array}$ & 300,42 & $28,00 \%$ & $28,07 \%$ \\
\hline Tembalang & 3984,21 & 8,99 & $0,23 \%$ & & $\begin{array}{c}0,00 \\
\%\end{array}$ & 183,67 & $4,61 \%$ & $4,84 \%$ \\
\hline Tugu & 3008,71 & 5,5 & $0,18 \%$ & 40,03 & $\begin{array}{c}1,33 \\
\%\end{array}$ & 186,17 & $6,19 \%$ & $7,70 \%$ \\
\hline
\end{tabular}

Sumber:Analisis, 2020

\section{2) Persentase Luasan RTH Publik Taman Dan Hutan Kota dan Kekurangannya}

Besaran persentase luasan RTH publik taman dan hutan kota dari gamparan capaian di Tabel 2, jika disandingkan dengan standar minimal luasan RTH publik taman dan hutan kota sebesar 12,5\% dari luas perkotaan, maka kekurangan RTH jenis ini akan sangat besar (-12,21\%) atau kurang 97,68\%. Kekurangan luasan RTH jenis ini, untuk masing-masing kecamatan dapat dilihat pada Tabel 2. Besarnya kekurangan RTH taman dan hutan kota ini selain akibat perubahan fungsi lahan taman kota juga pada pada tahun 2017 terdapat perubahan luasan hutan kota karena adanya koreksi kesalahan identifikasi berupa hutan produksi perhutani yang semula di plot sebagai hutan kota (bagian dari RTH publik) harus dikeluarkan. 
Tabel 2. Kekurangan Luasan RTH Taman dan Hutan Kota untuk Tiap-tiap Kecamatan di Kota Semarang Tahun 2020

\begin{tabular}{|l|c|c|c|c|c|c|}
\hline Kecamatan & $\begin{array}{c}\text { Luas } \\
\text { Kec. } \\
\text { (Ha) }\end{array}$ & $\begin{array}{c}\text { L RTH } \\
\text { Tm \& } \\
\text { HKa) }\end{array}$ & $\begin{array}{c}\text { Persentas } \\
\text { e Luasan } \\
\text { RTH }\end{array}$ & $\begin{array}{c}\text { L Min } \\
\text { RTH Tm } \\
\text { \& HK } \\
\text { (Ha) }\end{array}$ & $\begin{array}{c}\text { Kekuranga } \\
\text { n luasan } \\
\text { RTH Tm } \\
\text { \&HK }\end{array}$ & $\begin{array}{c}\text { Persentase } \\
\text { Kekuranga } \\
\text { n Luasan }\end{array}$ \\
\hline Banyumanik & 3055,62 & 17,1 & $0,56 \%$ & 611,12 & 594,02 & $-11,94 \%$ \\
\hline Candisari & 703,02 & 12,75 & $1,81 \%$ & 140,60 & 127,85 & $-10,69 \%$ \\
\hline $\begin{array}{l}\text { Gajahmungku } \\
\text { r }\end{array}$ & 959,7 & 3,55 & $0,37 \%$ & 191,94 & 188,39 & $-12,13 \%$ \\
\hline Gayamsari & 612,77 & 0 & $0,00 \%$ & 122,55 & 122,55 & $-12,50 \%$ \\
\hline Genuk & 2756,61 & 3,86 & $0,14 \%$ & 551,32 & 547,46 & $-12,36 \%$ \\
\hline Gunung Pati & 6084,21 & 0 & $0,00 \%$ & 1216,84 & 1216,84 & $-12,50 \%$ \\
\hline Mijen & 5887,7 & 0 & $0,00 \%$ & 1177,54 & 1177,54 & $-12,50 \%$ \\
\hline Ngaliyan & 4424,15 & 0 & $0,00 \%$ & 884,83 & 884,83 & $-12,50 \%$ \\
\hline Pedurungan & 2319,82 & 0 & $0,00 \%$ & 463,96 & 463,96 & $-12,50 \%$ \\
\hline $\begin{array}{l}\text { Semarang } \\
\text { Barat }\end{array}$ & 2222,76 & 1,49 & $0,07 \%$ & 444,55 & 443,06 & $-12,43 \%$ \\
\hline $\begin{array}{l}\text { Semarang } \\
\text { Selatan }\end{array}$ & 621,91 & 2,2 & $0,35 \%$ & 124,38 & 122,18 & $-12,15 \%$ \\
\hline $\begin{array}{l}\text { Semarang } \\
\text { Tengah }\end{array}$ & 535,39 & 2,92 & $0,55 \%$ & 107,08 & 104,16 & $-11,95 \%$ \\
\hline $\begin{array}{l}\text { Semarang } \\
\text { Timur }\end{array}$ & 559,46 & 1,32 & $0,24 \%$ & 111,89 & 110,57 & $-12,26 \%$ \\
\hline $\begin{array}{l}\text { Semarang } \\
\text { Utara }\end{array}$ & 1072,91 & 0,73 & $0,07 \%$ & 214,58 & 213,85 & $-12,43 \%$ \\
\hline Tembalang & 3984,21 & 8,99 & $0,23 \%$ & 796,84 & 787,85 & $-12,27 \%$ \\
\hline Tugu & 3008,71 & 5,5 & $0,18 \%$ & 601,74 & 596,24 & $-12,32 \%$ \\
\hline Sumber & & & & & \\
\hline
\end{tabular}

Sumber:Analisis, 2020

\section{3) Potensi RTH Sempadan Sungai dan Pemanfaatannya}

RTH fungsi khusus dalam Peraturan Menteri Pekerjaan Umum Nomor 05/PRT/M/2008, memiliki standar minimal 1,5\% dari luas perkotaan. Pada kasus Kota Semarang persentase luasan RTH ini melebihi standar minimal di semua kecamatan. Hal ini sangat berkebalikan dengan persentase luasan RTH publik jenis taman dan hutan kota yang sangat jauh dari angka standar minimal. Berkaiatan dengan upaya peningkatan angka capaian persentase luasan RTH taman dan hutan kota, potensi kelebihan ini bisa dialih fungsikan untuk menambah luasan RTH publik tersebut.

Pemanfaatan kelebihan luasan RTH fungsi tertentu ini harus tetap didasarkan pada kebijakan yang berlaku di Indonesia tanpa mengubah fungsi utama RTH fungsi tertentu. Dari sekian jenis RTH fungsi tertentu, hanya RTH ruang sempadan sungai yang relatif lebih memungkinkan digunakan untuk menambah luasan RTH publik taman dan hutan kota, dibanding dengan RTH sempadan rel, listrik tegangan tinggi dan sempadan pantai serta RTH makam. 
Tabel 3. Potensi Kelebihan Luasan (Melebihi Standar Minimum) Pada RTH Fungsi Khusus di Kota Semarang Perkecamatan Tahun 2020

\begin{tabular}{|l|c|c|c|}
\hline \multicolumn{1}{|c|}{ Kecamatan } & $\begin{array}{c}\text { Luas Eksisting } \\
\text { RTH Fungsi } \\
\text { Khusus }\end{array}$ & $\begin{array}{c}\text { Persentas } \\
\text { Luasan Fungsi } \\
\text { KhususRTH }\end{array}$ & $\begin{array}{c}\text { Kelebihan \% } \\
\text { luasan (Ideal } \\
\mathbf{1 , 5 \% )}\end{array}$ \\
\hline Banyumanik & 144,89 & $4,74 \%$ & $3,24 \%$ \\
\hline Candisari & 71,38 & $10,15 \%$ & $8,65 \%$ \\
\hline Gajahmungkur & 49,47 & $5,15 \%$ & $3,65 \%$ \\
\hline Gayamsari & 127,26 & $20,77 \%$ & $19,27 \%$ \\
\hline Genuk & 294,22 & $10,67 \%$ & $9,17 \%$ \\
\hline Gunung Pati & 191,24 & $3,14 \%$ & $1,64 \%$ \\
\hline Mijen & 210,04 & $3,57 \%$ & $2,07 \%$ \\
\hline Ngaliyan & 189,57 & $4,28 \%$ & $2,78 \%$ \\
\hline Pedurungan & 170,48 & $7,35 \%$ & $5,85 \%$ \\
\hline Semarang Barat & 232,59 & $10,46 \%$ & $8,96 \%$ \\
\hline Semarang Selatan & 74,46 & $11,97 \%$ & $10,47 \%$ \\
\hline Semarang Tengah & 27,99 & $5,23 \%$ & $3,73 \%$ \\
\hline Semarang Timur & 52,6 & $9,40 \%$ & $7,90 \%$ \\
\hline Semarang Utara & 300,42 & $28,00 \%$ & $26,50 \%$ \\
\hline Tembalang & 183,67 & $4,61 \%$ & $3,11 \%$ \\
\hline Tugu & 186,17 & $6,19 \%$ & $4,69 \%$ \\
\hline
\end{tabular}

Sumber:Analisis, 2020

Tabel 4. Luasan RTH Fungsi Khusus Per Jenis RTH Per Kecamatan di Kota Semarang

\begin{tabular}{|c|c|c|c|c|c|c|c|c|c|c|}
\hline \multirow[b]{2}{*}{ Kecamatan } & \multicolumn{10}{|c|}{ Luas Eksisting RTH Fungsi Khusus Per Jenis } \\
\hline & $\begin{array}{c}\text { RTH } \\
\text { Semp } \\
\text { d } \\
\text { Rel }\end{array}$ & $\begin{array}{c}\% \\
\text { Luas }\end{array}$ & $\begin{array}{c}\text { L RTH } \\
\text { Sempd } \\
\text { J. } \\
\text { Listrik }\end{array}$ & $\begin{array}{c}\% \\
\text { Luasa } \\
\text { n }\end{array}$ & $\begin{array}{c}\text { L } \\
\text { RTH } \\
\text { Sempd } \\
\text { Sungai }\end{array}$ & $\begin{array}{c}\% \\
\text { Luasa } \\
\text { n }\end{array}$ & $\begin{array}{c}\text { L } \\
\text { RTH } \\
\text { Semp } \\
\text { d. } \\
\text { Pantai }\end{array}$ & $\begin{array}{c}\% \\
\text { Luasa } \\
\text { n }\end{array}$ & $\begin{array}{c}\text { Pem } \\
\text { a- } \\
\text { kam } \\
\text { an }\end{array}$ & $\begin{array}{c}\% \\
\text { Luasa } \\
\text { n }\end{array}$ \\
\hline Banyu & & $0,00 \%$ & 109,16 & $\begin{array}{c}75,34 \\
\%\end{array}$ & 30,16 & $\begin{array}{c}20,82 \\
\%\end{array}$ & & $0,00 \%$ & 5,57 & $3,84 \%$ \\
\hline Can & 1,13 & $1,58 \%$ & 44 & $\begin{array}{c}81,87 \\
\%\end{array}$ & 1 & $8,56 \%$ & & $0,00 \%$ & 5,7 & $7,99 \%$ \\
\hline $\begin{array}{l}\text { Gajahı } \\
\text { ur }\end{array}$ & & $0,00 \%$ & 34,38 & $\begin{array}{c}69,50 \\
\%\end{array}$ & 10,12 & $\begin{array}{c}20,46 \\
\%\end{array}$ & & $0,00 \%$ & 4,97 & $\begin{array}{c}10,05 \\
\%\end{array}$ \\
\hline Gas & & 6 & 112,51 & $\begin{array}{c}88,41 \\
\%\end{array}$ & 5,24 & $4,12 \%$ & & $0,00 \%$ & 05 & $0,83 \%$ \\
\hline G & 7 & $\%$ & 210,16 & $\begin{array}{c}71,43 \\
\%\end{array}$ & 8 & $9,41 \%$ & 28,86 & $9,81 \%$ & 1,75 & $0,59 \%$ \\
\hline & & $0,00 \%$ & 144,71 & $\begin{array}{c}75,67 \\
\%\end{array}$ & 39,74 & $\begin{array}{c}20,78 \\
\%\end{array}$ & & $0,00 \%$ & 79 & $3,55 \%$ \\
\hline Mijer & & $0,00 \%$ & 173,81 & $\begin{array}{c}82,75 \\
\%\end{array}$ & 27,37 & $\begin{array}{c}13,03 \\
\%\end{array}$ & & $0,00 \%$ & 86 & $4,22 \%$ \\
\hline & & & 168,37 & $\begin{array}{c}88,82 \\
\%\end{array}$ & 14,44 & $7,62 \%$ & & $0,00 \%$ & 4 & $3,56 \%$ \\
\hline Pedur & 35,34 & $\begin{array}{c}20,73 \\
\%\end{array}$ & 91,65 & $\begin{array}{c}53,76 \\
\%\end{array}$ & 20,50 & $\begin{array}{c}12,02 \\
\%\end{array}$ & 20,5 & $\begin{array}{c}12,02 \\
\%\end{array}$ & 49 & $1,46 \%$ \\
\hline $\begin{array}{l}\text { Semarang } \\
\text { Barat }\end{array}$ & & 7 & 1 & $\begin{array}{c}58,23 \\
\%\end{array}$ & 14,17 & $09 \%$ & 59,19 & $\begin{array}{c}25,45 \\
\%\end{array}$ & 77 & $2,31 \%$ \\
\hline $\begin{array}{l}\text { Semarang } \\
\text { Selatan }\end{array}$ & 6,46 & $8,68 \%$ & 28,31 & $\begin{array}{c}38,02 \\
\%\end{array}$ & 5,53 & $7,43 \%$ & 5,93 & $7,96 \%$ & 28,23 & $\begin{array}{c}37,91 \\
\%\end{array}$ \\
\hline $\begin{array}{l}\text { Semarang } \\
\text { Tengah }\end{array}$ & 16,31 & $\begin{array}{c}58,27 \\
\%\end{array}$ & 4,44 & $\begin{array}{c}15,86 \\
\%\end{array}$ & 3,62 & $\begin{array}{c}12,93 \\
\%\end{array}$ & 3,62 & $\begin{array}{c}12,93 \\
\%\end{array}$ & & $0,00 \%$ \\
\hline
\end{tabular}




\begin{tabular}{|c|c|c|c|c|c|c|c|c|c|c|}
\hline \multirow[b]{2}{*}{ Kecamatan } & \multicolumn{10}{|c|}{ Luas Eksisting RTH Fungsi Khusus Per Jenis } \\
\hline & $\begin{array}{c}\text { RTH } \\
\text { Semp } \\
\text { d } \\
\text { Rel }\end{array}$ & $\begin{array}{c}\% \\
\text { Luas }\end{array}$ & $\begin{array}{c}\text { L RTH } \\
\text { Sempd } \\
\text { J. } \\
\text { Listrik }\end{array}$ & $\begin{array}{c}\% \\
\text { Luasa } \\
\mathbf{n}\end{array}$ & $\begin{array}{c}\text { L } \\
\text { RTH } \\
\text { Sempd } \\
\text { Sungai }\end{array}$ & $\begin{array}{c}\% \\
\text { Luasa } \\
\mathbf{n}\end{array}$ & $\begin{array}{c}\text { L } \\
\text { RTH } \\
\text { Semp } \\
\text { d. } \\
\text { Pantai }\end{array}$ & $\begin{array}{c}\% \\
\text { Luasa } \\
\text { n }\end{array}$ & $\begin{array}{c}\text { Pem } \\
\text { a- } \\
\text { kam } \\
\text { an }\end{array}$ & $\begin{array}{c}\% \\
\text { Luasa } \\
\text { n }\end{array}$ \\
\hline $\begin{array}{l}\text { Semarang } \\
\text { Timur }\end{array}$ & 14,26 & $\begin{array}{c}27,11 \\
\%\end{array}$ & 22,48 & $\begin{array}{c}42,74 \\
\%\end{array}$ & 7,93 & $\begin{array}{c}15,08 \\
\%\end{array}$ & 7,93 & $\begin{array}{c}15,08 \\
\%\end{array}$ & & $0,00 \%$ \\
\hline $\begin{array}{l}\text { Semarang } \\
\text { Utara }\end{array}$ & 16,36 & $5,45 \%$ & 129 & $\begin{array}{c}42,94 \\
\% \\
\end{array}$ & 10,43 & $3,47 \%$ & 144,25 & $\begin{array}{c}48,02 \\
\% \\
\end{array}$ & 0,38 & $0,13 \%$ \\
\hline Tembalang & & $0,00 \%$ & 100,32 & $\begin{array}{c}54,62 \\
\%\end{array}$ & 39,52 & $\begin{array}{c}21,52 \\
\%\end{array}$ & & $0,00 \%$ & 43,83 & $\begin{array}{c}23,86 \\
\%\end{array}$ \\
\hline Tugu & & $0,00 \%$ & 106,29 & $\begin{array}{c}57,09 \\
\%\end{array}$ & 14,7 & $7,90 \%$ & 61,28 & $\begin{array}{c}32,92 \\
\%\end{array}$ & 3,9 & $2,09 \%$ \\
\hline
\end{tabular}

Sumber:Analisis, 2020

Luas RTH sempadan sungai, untuk masing-masing kecamatan berdasarkan Tabel 4, memiliki potensi untuk meningkatkan luasan RTH taman dan hutan kota yang capaiannya masih jauh dari standar minimal yang ditetapkan di Peraturan Menteri Pekerjaan Umum Nomor 05/PRT/M/2008. Luasan ruang sempadan sungai di tiap kecamatan ini berkisar antara 3 -39 Ha. Jumlah ini sangat jauh jika dibandingkan dengan luasan eksisting taman dan hutan kota pada Tabel 1. Sebaran potensi RTH Sempadan sungai ini secara spasial dapat dilihat pada peta sebaran RTH Sempadan Sungai sebagai berikut:

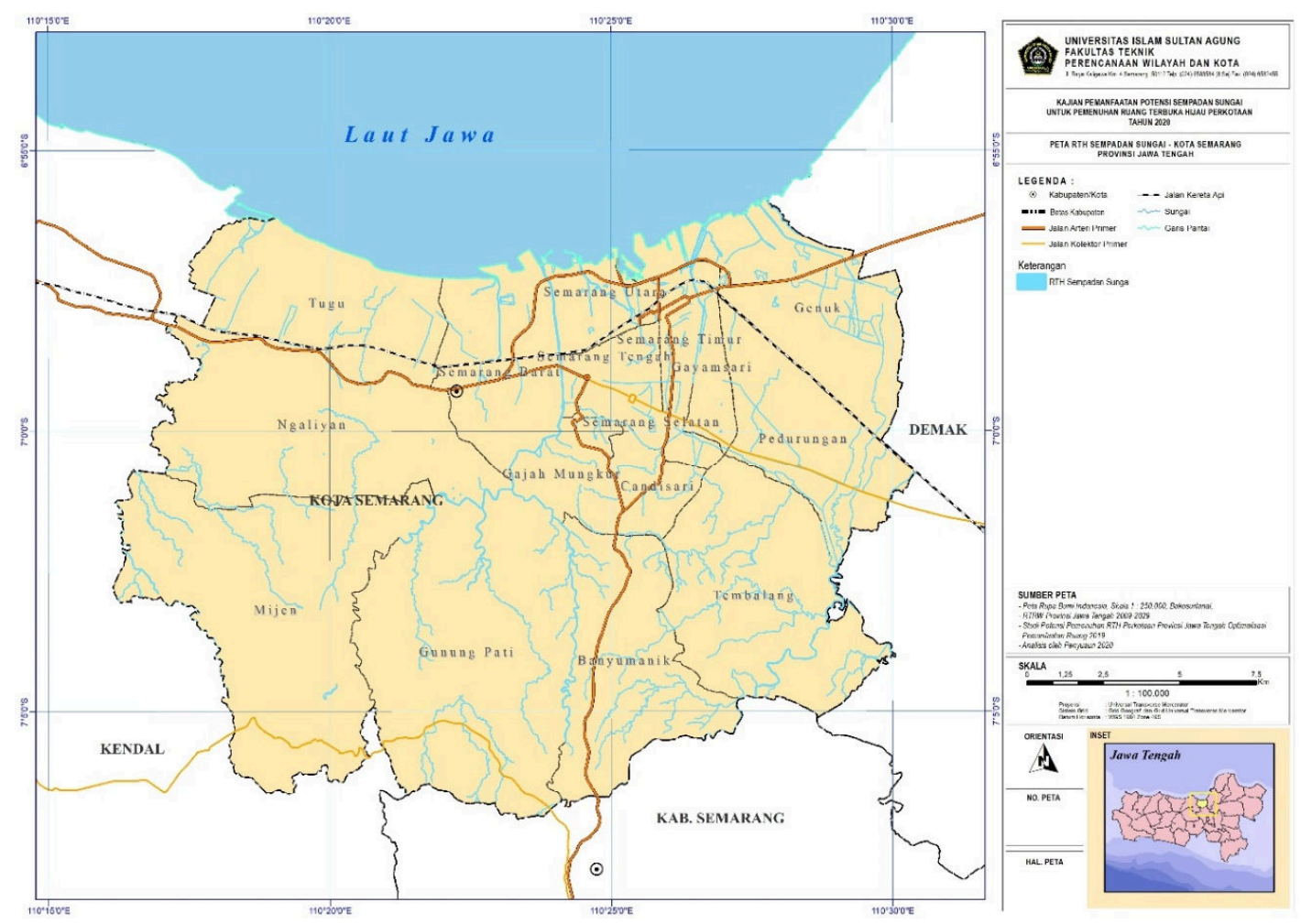

Gambar 2. Peta Sebaran RTH Sempadan Sungai di Semarang 
Upaya menambahan RTH taman dan hutan kota yaitu dengan memanfaatkan ruang sempada sungai tentu akan membawa konsekuensi lain. Hal ini karena ruang sempadan yang selama ini ditetapkan sebagai kawasan lindung, dalam prakteknya telah banyak berubah menjadi kawasan budidaya seperti pada Tabel 6 .

Tabel 6. Pemanfaatan Ruang di Kawasan Sempadan Sungai Kota Semarang

\begin{tabular}{|l|c|}
\hline \multicolumn{1}{|c|}{ Penggunaan Lahan } & Luas (Ha) \\
\hline Pemukiman & 158,09 \\
\hline Pertanian Lahan Kering Campur & 66,18 \\
\hline Pertanian Lahan Kering & 3,33 \\
\hline Sawah & 10,59 \\
\hline Tambak & 14,15 \\
\hline Hutan Tanaman & 18,81 \\
\hline Bandara / Pelabuhan & 1,52 \\
\hline Hutan Mangrove Sekunder & 1,60 \\
\hline Perkebunan & 2,27 \\
\hline Tanah Terbuka & 0,71 \\
\hline
\end{tabular}

Sumber:Analisis, 2020

Penggunaan kawasan sempadan sungai yang paling besar adalah untuk ruang permukiman, baik permukiman kumuh maupun permukiman swadaya, sehingga kemungkinan besar untuk memanfaatkan kawasan ini tentu harus dibarengi dengan penertiban dan penataan ulang kawasan permukiman di sempadan sungai, seperti yang sudah dilakukan di sempadan Sungai Banjir Kanal Barat dan Timur Kota Semarang. Beberapa gambaran pemanfaatan ruang di kawasan sempadan sungai yang saat ini sudah dimanfaatkan untuk taman kota ini dapat dilihat juga pada Gambar 2. berikut ini:

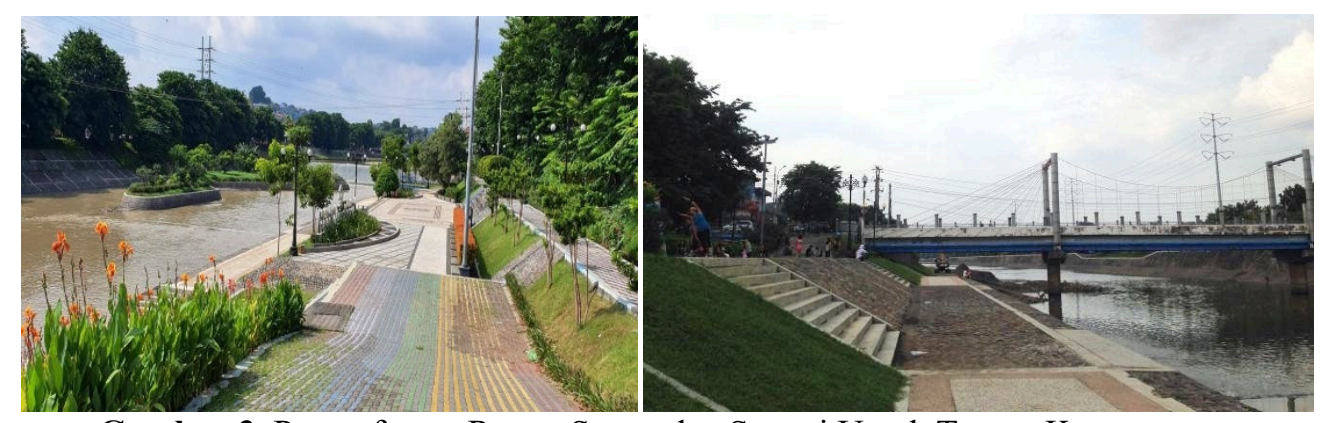

Gambar 3. Pemanfaatan Ruang Sempadan Sungai Untuk Taman Kota Sumber:Analisis, 2020

Perwujudan ruang sempadan sungai sebagai pemenuhan RTH taman dan hutan kota seperti pada Gambar 3 memerlukan dana yang besar untuk pembebasan status kepemilikan lahan, selain itu juga memerlukan kesepakatan dari para pemangku kewenangan seperti pengelola sungai di Kota Semarang. Hal ini karena kewenangan sungai tidak dimiliki oleh 
Pemerintah Kota Semarang. Penggunaan ruang sempadan sungai untuk menambah prosentase luasan TH di kota ZSemarang di masa datang tentu memerlukan koordinasi yang baik dalam pembebasan, pembangunan, pengelolaan hingga terwujudnya ruang sempadan sungai menjadi RTH taman dan hutan kota.

\section{KESIMPULAN DAN SARAN}

Beberapa kesimpulan yang dapat ditarik dari kajian ini adalah:

1) Persentase luasan RTH publik taman dan hutan kota untuk Kota Semarang masih dangan jauh dari standar minimal yang ditetapkan, yaitu hanya $12,5 \%$ dari luas perkotaan;

2) Terdapat potensi ruang terbuka hijau fungsi khusus berupa sempadan sungai dengan luas di tiap kecamatan antar 3-39 Ha, dan sebagian masih bisa dialih fungsikan untuk pemenuhan RTH publik taman dan hutan kota;

3) Terdapat beberapa jenis pemanfaatan ruang sempadan sungai, tidak hanya sebagai kawasan lindung setempat, tetapi sebagian sudah berkembang untuk kegiatan budidaya lainnya seperti permukiman, tambak, sawah pertanian lahan kering dan lainnya, dengan beragam status kepemilikan.

Saran yang diberikan dari hasil kajian ini antar lain:

1) Pemanfaatan ruang sempadan sungai untuk menambah luasan RTH publik taman dan hutan kota, dapat dilakukan dengan mengikuti arahan peraturan perundangan yang berlaku;

2) Pemanfaatan RTH untuk taman dan hutan kota (fungsi tertentu jangan sampai mengganggu fungsi utama kawasan sempadan sungai yaitu sebagai pelindung ekosistem, pelindung area discharge air maupun pelindung terhadap bencana serta akses publik;

3) Studi ini masih memiliki banyak keterbatasan sehingga perlu ada kajian lanjutan terkait dengan status peruntukan dan kepemilikan lahan pada ruang sempadan.

\section{DAFTAR PUSTAKA}

Abu Kasim, J., Yusof, J. M., \& Zulhaidi Mohd Shafri, H. (2019). The Many Benefits Of Urban Green Spaces Junainah Abu Kasim 1*, Mohd Johari Mohd Yusof 1, Helmi Zulhaidi Mohd Shafri 2 1. Journal of Infrastructure Development, 2(1), 103-116.

Alifia, N. (2016). Identifikasi Letak Dan Jenis Ruang Permukiman Perkotaan. Langkau Betang, 3(2), 25-38.

Fadhila, C. H., Murtilaksono, K., \& Munibah, K. (2019). Arahan Pemenuhan Ruang 
Terbuka Hijau Kota Banda Aceh. Tataloka, 21(1), 180. https://doi.org/10.14710/tataloka.21.1.180-191

Nugroho, M. L. E. (2015). Problematika Penyediaan Ruang Terbuka Hijau di Kota Semarang. Urban Studies And Development Pembangunan Inklusif: Menuju Ruang Dan Lahan Perkotaan Yang Berkeadilan, 139 - 151.

Pemerintah Repulik Indonesia. (2008). No Title Peraturan Menteri Pekerjaan Umum Nomor: 05/PRT/M/2008 Tentang Pedoman Penyediaan Dan Pemanfaatan Ruang Terbuka Hijau Di Kawasan Perkotaan. Kementrian Pekerjaan Umum.

Rakhshandehroo, M., Johari, M., \& Yusof, M. (2018). The Environmental Benefits Of Urban Open Green Spaces. Alam Cipta, 10(1), 10-16.

Setyani, W., Risma, S., Sitorus, P., \& Panuju, R. (2017). Analisis Ruang Terbuka Hijau Dan Kecukupannya Di Kota Depok An analysis of Greenery Open Space and Its Adequacy in Depok City. 1(1), 121-127.

Siwi, N. (2018). Pentingnya Ruang Terbuka Hijau dalam Tata Ruang Perkotaan Sebagai Sudut. (May). Retrieved from t: https://www.researchgate.net/publication/325312206\%0APentingnya

Ahmad, Tedy (2020) Kapan Waktu Terbaik Berjemur, Sebelum atau Setelah Pukul 10.00 WIB?. Sindonews.com. Sabtu, 04 April 2020 - 07:51 WIB

https://daerah.sindonews.com/artikel/jateng/24373/kapan-waktu-terbaik-berjemursebelum-atau-setelah-pukul-1000-wib diakses pada 20 Juli, 2020: 14.30 